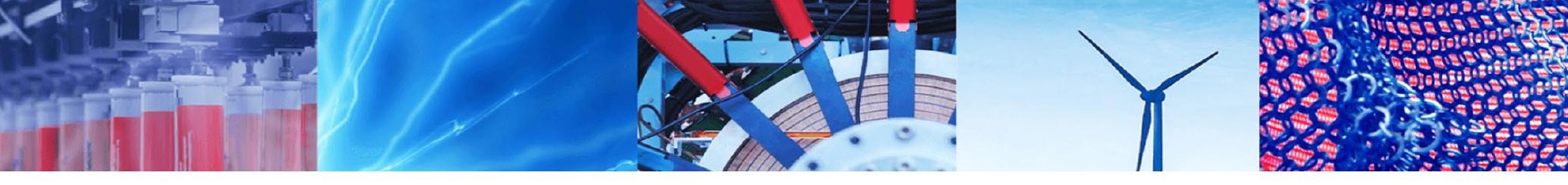

Research Article

\title{
Parametric effect on electrical discharge treatment of magnesium alloy with powder composite electrode
}

\author{
U. Elaiyarasan ${ }^{1} \cdot$ V. Satheeshkumar ${ }^{2} \cdot$ C. Senthilkumar ${ }^{3}$
}

Received: 16 December 2019 / Accepted: 4 February 2020 / Published online: 12 February 2020

(c) Springer Nature Switzerland AG 2020

\begin{abstract}
In this present investigation, an attempt has been made to deposit the composite coating on ZE41A magnesium alloy using tungsten carbide and Nickel powder metallurgy electrode by electro discharge deposition. The experiment is conducted using ordinary EDM and EDM oil as dielectric fluid. Compaction load, current and pulse on time are selected as the input parameters that influences the characteristics such as deposition rate (DR) and electrode wear rate (EWR). Micro hardness of the deposited is evaluated using vicker hardness tester. Mathematical models are developed to study the effect of process parameters on the responses. It is revealed that the DR and EWR increases with increase in current and pulse on time at low compaction load, but it decreases at high compaction load. Maximum DR and EWR are achieved at compaction load (150 MPa), current (4 A) and pulse on time (90 $\mu \mathrm{s})$. Maximum hardness values (772 HV) is achieved at surface deposited with low compaction and high current and pulse on time. Scanning electron microscope and Energy dispersive spectroscope are carried out in the deposited workpiece to study microstructural and confirm the presence of electrode materials respectively.
\end{abstract}

Keywords Electrical discharge deposition · Deposition rate $\cdot$ Response surface methodology $\cdot$ Compaction load $\cdot$ Micro hardness $\cdot$ SEM

\section{Introduction}

In recent scenario, surface modified materials play an important role in engineering applications such as aircraft, aerospace and automobile. The surfaces of the required workpiece materials have been modified using different surface modification methods in order to enhance surface properties such as wear, corrosion and mechanical properties etc. [1]. Surface modification processes are classified into the two methods; one is modification by deposition or coating of material and another one is development of new alloy by casting and powder metallurgy. In present year, modified surface using deposition or coating widely applied in the diverse fields of application. Various surface modification methods such as physical vapour deposition (PVD), chemical vapour deposition (CVD), plasma spraying and high velocity oxy fuel (HVOF) are adopted to enhance the surface properties [2]. These techniques widely applied in the several industries due to its accuracy. Though, it needs special equipment to control the coating characteristics in order to enhance the properties. To overcome this problem the electrical discharge deposition is the capable technique to improve the surface properties of the workpiece. Electrical discharge machining (EDM) is the well acknowledged non traditional machining process used to machining the hard material with high precision and accuracy. EDM is not only used for machining purpose but also for depositing the uniform coating layer on the surface with required wear

\footnotetext{
$\triangle$ U. Elaiyarasan, elaiyarasan555@gmail.com | 'Department of Mechanical Engineering, Karpaga Vinayaga College of Engineering and Technology, Madhuranthagam 603308, India. ${ }^{2}$ Department of Mechanical Engineering, Government College of Engineering, Salem 636011, India. ${ }^{3}$ Department of Mechanical Engineering, University College of Engineering, Panruti 607106, India.
} 
Table 1 Chemical composition of ZE41A magnesium alloy

\begin{tabular}{llllllllll}
\hline $\mathrm{Si}$ & $\mathrm{Cu}$ & $\mathrm{Zn}$ & $\mathrm{Zr}$ & $\mathrm{Fe}$ & $\mathrm{TRE}$ & $\mathrm{Ni}$ & $\mathrm{Mn}$ & $\mathrm{Al}$ & $\mathrm{Mg}$ \\
\hline 0.003 & 0.002 & 3.80 & 0.60 & 0.004 & 1.18 & 0.002 & 0.003 & 0.006 & Bal \\
\hline
\end{tabular}

resistance material [3]. This innovative method is called as electrical discharge deposition (EDD). In this process, the electrode material is deposited over the surface by passing continues electric spark between the electrode and workpiece. During this process, the electrode materials is melted and deposited on the surface as a coating layer within a minute [4]. Several investigations have been studied on the different workpiece material and electrode material but optimization of such modification method is very limited. Arun et al. [5] developed the uniform coating on the base substrate using electrical discharge coating with $\mathrm{Ni} / \mathrm{W}$ powder metallurgy semi sintered electrode. It was studied that the migration of electrode materials towards workpiece material and tribological behaviour of coated material. It is revealed that the rate of migration increased at electrode prepared with low pressure. Tyagi et al. [6] have implemented electrical discharge treatment to modify the surface of stainless steel using tungsten disulfide $\left(\mathrm{WS}_{2}\right)$ and copper $(\mathrm{Cu})$ powder mixed electrode. In this experiment, the electrodes have been prepared in the different proportion. RSM is proposed to design the experiments and three parameters such as powder composition, duty factor and discharge current have selected as the input variables and the responses were rate of deposition and micro hardness. It was found that the deposition rate and micro hardness increases with increasing the addition of tungsten disulfide. Gill and Kumar [7] improved the micro hardness of the electro discharge alloyed die steel coated with $\mathrm{Cu}-\mathrm{Ni}-\mathrm{Cr}$ powder metallurgy electrode. Experiment was carried out under different parametric condition such as current, pulse duration and compaction load. It was found that the alloyed surface using powder metallurgy was improved by $96.3 \%$ when compare with base material. Energy dispersive spectroscope analysis is carried out on the alloyed surface to confirm the presence of migrated electrode material. Tijo et al. [8] investigated the surface modification of AISI 1020 steel using electrical discharge coating with powder compact electrode. Electrodes were prepared using $\mathrm{TiC}(60 \%)$ and $\mathrm{Cu}(40 \%)$ powders in different compaction load. The influence of current and pulse on time on the material deposition and surface roughness of the coated surface was evaluated. It was observed that the rate of deposition and hardness increases with increase in current and pulse on time. From studied literature, EDM parameters were optimized using taguchi technique but optimization of EDD parameters is still limited. In this research, magnesium alloy is selected as the workpiece material and tungsten carbide and nickel powder are selected as the electrode materials for fabricating electrode through powder metallurgy technique. Effect of compaction load, current and pulse on time on the DR and EWR are studied. Central composite design of response surface methodology is introduced to plan experiments and optimize the parameters on the responses.

\section{Experimentation}

\subsection{Materials and methods}

Magnesium alloys are light weight structural material extensively utilised in the several application such as automobile and aerospace. In this work, ZE41A magnesium alloy is selected as the base material and its chemical

Fig. 1 Compacted cylindrical electrode used for EDD

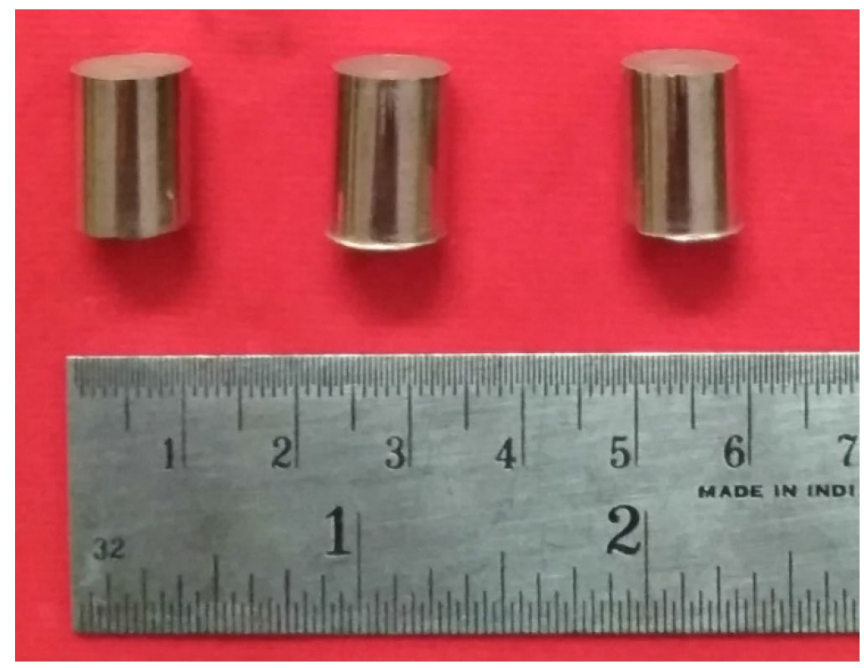




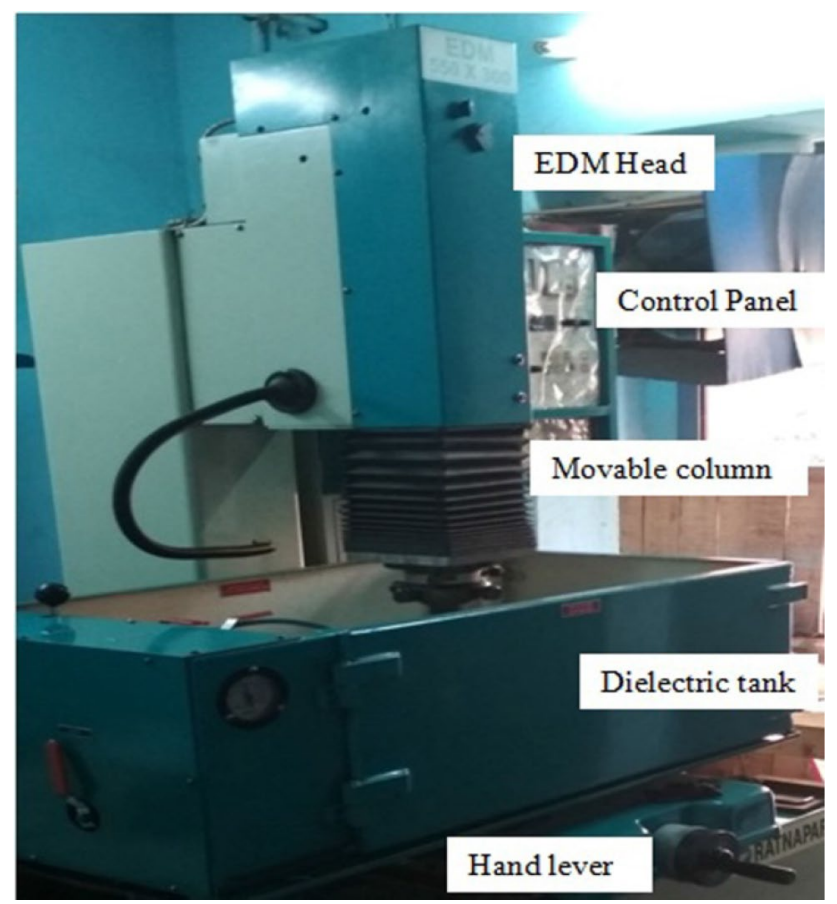

Fig. 2 EDM machine used in this study

Table 2 Factors and their levels used in this study

\begin{tabular}{llccc}
\hline Parameters & Unit & \multicolumn{2}{l}{ Levels } & \\
\cline { 3 - 5 } & & Low (-1) & Medium (0) & High (1) \\
\hline Compaction load (CL) & $\mathrm{MPa}$ & 150 & 175 & 200 \\
Current (I) & $\mathrm{Amp}$ & 2 & 3 & 4 \\
Pulse on time (Ton) & $\mu \mathrm{s}$ & 50 & 70 & 90 \\
\hline
\end{tabular}

composition is shown in Table 1. Tungsten carbide and nickel are selected as the electrode material. The selected electrode powders are mixed in the combination of WC70 Ni30 (wt\%) using mortar and pestle for $3 \mathrm{~h}$. Then the mixed powders are pressed in hydraulic press using punch and die system for 10 min with three different loads. The diameter of the punch and die system is $10 \mathrm{~mm}$. Then the compacted solid is removed slowly from the die. The compacted cylindrical electrode for EDC is shown in Fig. 1.

Electrical discharge coating experiments is carried out using 5530 EDM E-series machine as shown in Fig. 2 and EDM oil used as the dielectric fluid. Design tool used in this study is central composite design of response surface methodology. Three parameters and three levels are selected to carry out the experiments and tabulated in
Table 2. Before conducting experiments, the workpiece has been machined in the square size $(20 \mathrm{~mm} \times 20 \mathrm{~mm})$ using surface grinder to make smooth surface finish and it is polished well with 1500 grit abrasive emery sheet. Hardness of the ZE41A magnesium alloy is $68 \mathrm{HB}$. The experiment is conducted as per the design developed through RSM tool and each experiment takes fixed time interval of $10 \mathrm{~min}$. The workpiece and electrode has been weighed using SF400D weighing machine with accuracy of $0.001 \mathrm{~g}$. The weight of the electrode and workpiece are recorded before and after experiments for calculating the DR and EWR.

\section{Response surface methodology}

Response surface methodology is the collection of mathematical technique applied for analyzing and modeling the problem. In which mathematical models has been developed for responses. The main objective of the RSM tool is to minimize the number of experiments and determine optimal parameter during the EDD process. Process parameters have been evaluated by the empirical model developed by RSM and second order polynomial equation is given in Eq. 1.

$Z_{u}=a_{o}+\sum_{i=1}^{k} a_{i} x_{i}+\sum_{i=1}^{k} a_{i i} x_{i}^{2}+\sum_{j>1}^{k} a_{i j} x_{i} x_{j}$

$Z_{u}$ output characteristics such as DR and EWR, $a_{i}$ linear effect of $x_{i}, a_{i i}$ quadratic effect of $x_{i}, b_{i j}$ interaction effect between the $x_{i}$ and $x_{j}$.

The second term of the polynomial equation represents the linear effect, third term for quadratic effect and fourth term for interaction effect. Compaction load, current and pulse on time are selected as the parameters and the output characteristics are DR and EWR. Experiments were conducted as per the design and results were recorded in Table 3. The experiments were completed by MINITAB 17.0 statistical software.

\subsection{Mathematical modeling of DR and EWR}

Characteristics such as DR and EWR and the parameters such as compaction load (CL), current (I) and pulse on time (Ton) have been applied in the modeling. The empirical models are developed to determine the effect of parameters on DR and EWR is given Eqs. 2 and 3 respectively.

$$
\begin{aligned}
\mathrm{DR}= & 2.12061+0.01969 \mathrm{CL}+0.22349 \mathrm{I}+0.00510 \text { Ton }-0.00004 \mathrm{CL} * \mathrm{CL}-0.01623 \mathrm{I} * \mathrm{I} \\
& +0.00005 \text { Ton } * \text { Ton }+0.00083 \mathrm{CL} * \mathrm{I}-0.00007 \mathrm{CL} * \text { Ton }+0.00079 \mathrm{I} * \text { Ton } \\
\mathrm{R}^{2}= & 95.06
\end{aligned}
$$


Table 3 Experimental values recorded as per design matrix

\begin{tabular}{|c|c|c|c|c|c|}
\hline \multirow[t]{2}{*}{ Ex. no } & \multicolumn{3}{|c|}{ Process parameter } & \multicolumn{2}{|l|}{ Response } \\
\hline & $\begin{array}{l}\text { Compac- } \\
\text { tion load } \\
(\mathrm{MPa})\end{array}$ & Current (A) & $\begin{array}{l}\text { Pulse on } \\
\text { time }(\mu \mathrm{s})\end{array}$ & $\mathrm{DR}(\mathrm{g} / \mathrm{min})$ & $\begin{array}{l}\text { EWR (g/ } \\
\text { min) }\end{array}$ \\
\hline 1 & 150 & 2 & 50 & 0.031068 & 0.177182 \\
\hline 2 & 200 & 2 & 50 & 0.070068 & 0.072182 \\
\hline 3 & 150 & 4 & 50 & 0.109068 & 0.238182 \\
\hline 4 & 200 & 4 & 50 & 0.073068 & 0.173182 \\
\hline 5 & 150 & 2 & 90 & 0.147068 & 0.315182 \\
\hline 6 & 200 & 2 & 90 & 0.061068 & 0.240182 \\
\hline 7 & 150 & 4 & 90 & 0.296800 & 0.606182 \\
\hline 8 & 200 & 4 & 90 & 0.119000 & 0.575810 \\
\hline 9 & 150 & 3 & 70 & 0.129542 & 0.483200 \\
\hline 10 & 200 & 3 & 70 & 0.082540 & 0.383200 \\
\hline 11 & 175 & 2 & 70 & 0.080727 & 0.195273 \\
\hline 12 & 175 & 4 & 70 & 0.148000 & 0.391273 \\
\hline 13 & 175 & 3 & 50 & 0.108560 & 0.135868 \\
\hline 14 & 175 & 3 & 90 & 0.188640 & 0.405258 \\
\hline 15 & 175 & 3 & 70 & 0.145200 & 0.347250 \\
\hline 16 & 175 & 3 & 70 & 0.138500 & 0.356800 \\
\hline 17 & 175 & 3 & 70 & 0.133780 & 0.345600 \\
\hline 18 & 175 & 3 & 70 & 0.139500 & 0.349870 \\
\hline 19 & 175 & 3 & 70 & 0.138500 & 0.342300 \\
\hline 20 & 175 & 3 & 70 & 0.132700 & 0.346980 \\
\hline
\end{tabular}

The analysis of variance (ANOVA) test and $\mathrm{F}$ test have been performed to confirm the goodness of fit for the empirical model. $\mathrm{F}$ ratio value is calculated by the mean sum of square of source and experimental error. In which the lack of fit for calculated $F$ value is compared with the standard $F$ ratio value to determine the adequacy of empirical models developed for responses. Lack of fit suggested that the empirical model is statistically significant for analysis of DR and EWR. The $R^{2}$ value for DR and EWR are 95.06 and 98.10 respectively, which means that the regression model gives the great justification for the characteristics. In the ANOVA table, if the $P$ value is less than the 0.05 ( $P=0.05$, or $95 \%$ confidence) the developed model is statistically significant. The ANOVA table for the quadratic model for DR and EWR are given in Tables 4 and 5. The standard $F$ distribution percentage point for confidence level limits for $95 \%$ and $99 \%$ are 4.06 and 7.87 respectively [9]. From the ANOVA tables, the $\mathrm{F}$ point for lack fit is 3.68 and 3.25 respectively which is smaller than the standard $F$ value, thus the developed models are adequate. The normal probability plots drawn for DR and EWR are Figs. 3 and 4 respectively to study the distribution of the residuals. From the plot it is observed that the residuals are falling on a straight line, which means that the errors are normally distributed and the regression model is fairly adequate. In the ANOVA tables, the $P$ values of linear, quadratic and interaction is less than the 0.05 . Thus effect on DR and EWR are significant.

$$
\begin{aligned}
\mathrm{EWR}= & 3.57296-0.05133 \mathrm{CL}+0.15250 \mathrm{I}+0.02247 \mathrm{Ton}+0.00014 \mathrm{CL} * \mathrm{CL} \\
& -0.05523 \mathrm{I} * \mathrm{I}-0.00019 \text { Ton } * \text { Ton }+0.00042 \mathrm{CL} * \mathrm{I}+0.00002 \mathrm{CL} * \text { Ton }+0.00290 \mathrm{I} * \text { Ton } \\
\mathrm{R}^{2}= & 98.10
\end{aligned}
$$

Table 4 ANOVA test result for deposition rate

\begin{tabular}{lrlllrl}
\hline Source & DF & Seq SS & Adj SS & Adj MS & F & $P$ \\
\hline Regression & 9 & 0.058163 & 0.058163 & 0.006463 & 137.28 & 0.000 \\
Linear & 3 & 0.039846 & 0.010141 & 0.003380 & 71.81 & 0.000 \\
CL & 1 & 0.009474 & 0.003272 & 0.003272 & 69.52 & 0.000 \\
I & 1 & 0.012669 & 0.002396 & 0.002396 & 50.90 & 0.000 \\
Ton & 1 & 0.017703 & 0.000413 & 0.000413 & 8.78 & 0.014 \\
Square & 3 & 0.003936 & 0.003936 & 0.001312 & 27.87 & 0.000 \\
CL*CL & 1 & 0.002757 & 0.001657 & 0.001657 & 35.21 & 0.000 \\
I*I & 1 & 0.000287 & 0.000724 & 0.000724 & 15.38 & 0.003 \\
Ton ${ }^{*}$ Ton & 1 & 0.000892 & 0.000892 & 0.000892 & 18.95 & 0.001 \\
Interaction & 3 & 0.014381 & 0.014381 & 0.004794 & 101.83 & 0.000 \\
CL*I & 1 & 0.003478 & 0.003478 & 0.003478 & 73.88 & 0.000 \\
CL*Ton & 1 & 0.008898 & 0.008898 & 0.008898 & 189.01 & 0.000 \\
I*Ton & 1 & 0.002005 & 0.002005 & 0.002005 & 42.60 & 0.000 \\
Residual error & 10 & 0.000471 & 0.000471 & 0.000047 & & \\
Lack-of-fit & 5 & 0.000370 & 0.000370 & 0.000074 & 3.68 & 0.089 \\
Pure error & 5 & 0.000100 & 0.000100 & 0.000020 & &
\end{tabular}


Table 5 ANOVA test results for electrode wear rate

\begin{tabular}{lrlllrl}
\hline Source & DF & Seq SS & Adj SS & Adj MS & F & $P$ \\
\hline Regression & 9 & 0.360262 & 0.360262 & 0.040029 & 780.80 & 0.000 \\
Linear & 3 & 0.292216 & 0.025558 & 0.008519 & 166.18 & 0.000 \\
CL & 1 & 0.014090 & 0.022248 & 0.022248 & 433.96 & 0.000 \\
I & 1 & 0.096949 & 0.001116 & 0.001116 & 21.76 & 0.001 \\
Ton & 1 & 0.181176 & 0.008024 & 0.008024 & 156.51 & 0.000 \\
Square & 3 & 0.039643 & 0.039643 & 0.013214 & 257.76 & 0.000 \\
CL*CL & 1 & 0.000115 & 0.019729 & 0.019729 & 384.82 & 0.000 \\
I* I & 1 & 0.022824 & 0.008388 & 0.008388 & 163.61 & 0.000 \\
Ton ${ }^{*}$ Ton & 1 & 0.016704 & 0.016704 & 0.016704 & 325.83 & 0.000 \\
Interaction & 3 & 0.028402 & 0.028402 & 0.009467 & 184.67 & 0.000 \\
CL ${ }^{*}$ I & 1 & 0.000895 & 0.000895 & 0.000895 & 17.46 & 0.002 \\
CL* Ton & 1 & 0.000522 & 0.000522 & 0.000522 & 10.18 & 0.010 \\
I*Ton & 1 & 0.026985 & 0.026985 & 0.026985 & 526.36 & 0.000 \\
Residual error & 10 & 0.000513 & 0.000513 & 0.000051 & & \\
Lack-of-fit & 5 & 0.000392 & 0.000392 & 0.000078 & 3.25 & 0.111 \\
Pure error & 5 & 0.000121 & 0.000121 & 0.000024 & & \\
Total & 19 & 0.360774 & & & & \\
\hline
\end{tabular}

Fig. 3 Normal probability plot for DR

\section{Result and discussion}

\subsection{Effect of parameters on DR and EWR}

Figures 5 and 6 depict the mean effect plot for DR and EWR respectively, in which the values of DR and EWR are low at the initial condition of current ( $2 A)$ and pulse on time $(50 \mu \mathrm{s})$, but higher at low compaction load (150 MPa). At low compaction, the mechanical bonding between the powder particles is very low. Therefore during EDD process, high quantity of powder particles disintegrated from the electrode and deposited over the surface of the workpiece. Similarly, deposition rate is high in the surface deposited with electrode prepared at low compaction load as stated by Walia [10]. Conversely, electrodes prepared with high compaction load the bonding of the particles in the electrode are very high. Hence the electrode material with minimum quantity was deposited on the workpiece. Scanning electron microscope (SEM) microstructure of the deposited surface was observed in the different experimental conditions as shown in Fig. 7a-c. Figure 7a shows the SEM image for pores indentified in the surface deposited in the parameter of $150 \mathrm{MPa}, 4 \mathrm{~A}$ and 
Fig. 4 Normal probability plot for EWR

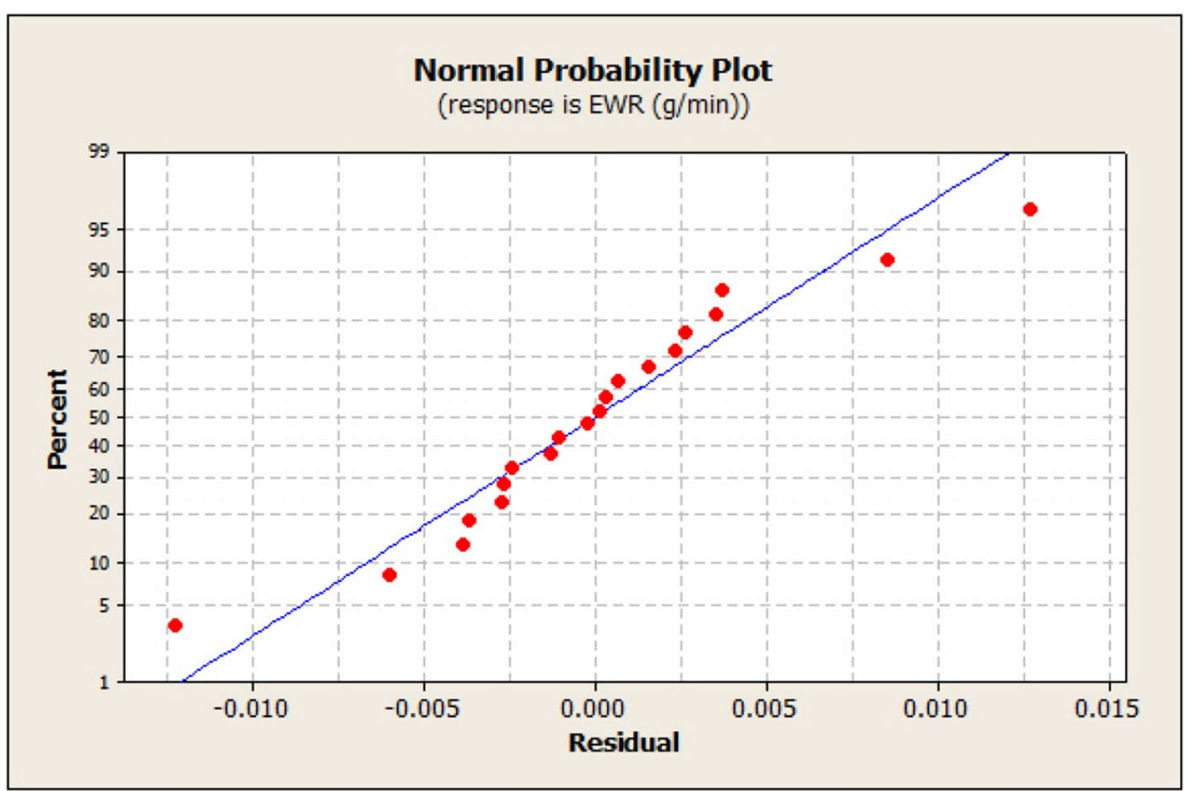

Fig. 5 Mean effect plot for DR

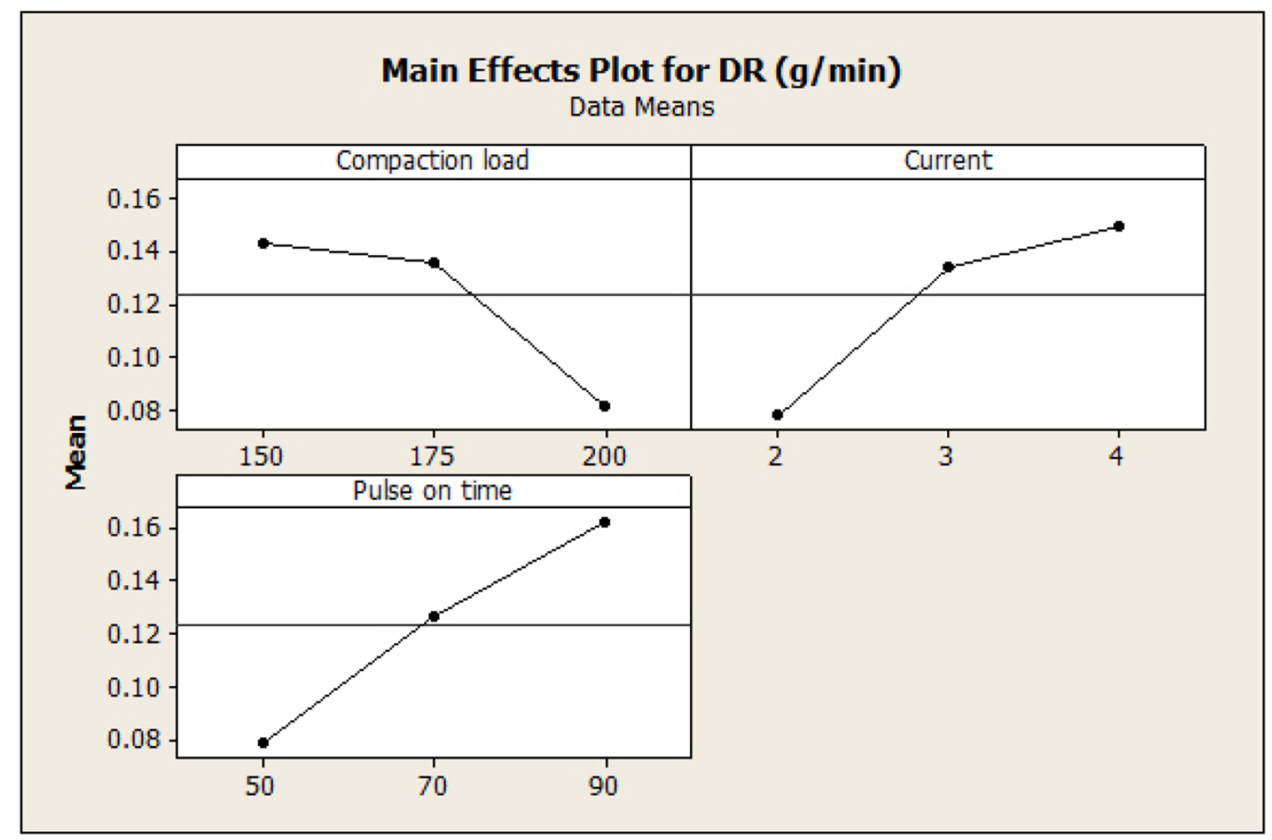

$90 \mu$ s. Similarly, Fig. 7b illustrates the craters at $175 \mathrm{MPa}$, $3 \mathrm{~A}$ and $70 \mu \mathrm{s}$ and globules was observed in the parametric condition of $200 \mathrm{MPa}, 2 \mathrm{~A}$ and $50 \mu$ s as depicted in Fig. 7c The minimum and maximum coating layer thickness achieved in the deposited surface are $78 \mu \mathrm{m}$ and $119 \mu \mathrm{m}$ respectively. Surface roughness $(6.89 \mu \mathrm{m})$ of the deposited surface was high at $150 \mathrm{MPa}, 4 \mathrm{~A}$ and $90 \mu \mathrm{s}$, because several numbers of pores formed in the condition. Minimum Surface roughness $(4.35 \mu \mathrm{m})$ was achieved at $200 \mathrm{MPa}$, $2 \mathrm{~A}$ and $50 \mu \mathrm{s}$, because uniform distribution formed with small sized globules. An electrode materials presented on the surface is confirmed by EDS peak plot and is shown in Fig. 8. This workpiece was deposited in the parametric condition of compaction load (150 MPa), current (4 A) and pulse on time $(90 \mu \mathrm{s})$. Similarly, when current increases the DR and EWR increases due its strength of spark density. At lower current setting insufficient electric spark is produced, hence erosion of electrode materials is poor. But high current increased the DR and EWR because of higher spark intensity. Similarly, it was concluded that the when current increases EWR increases [11]. Hence large amount of electrode particle eroded and deposited on the workpiece and increased the roughness of the deposited surface due to formation of bigger and deep craters. As 
Fig. 6 Mean effect plot for EWR
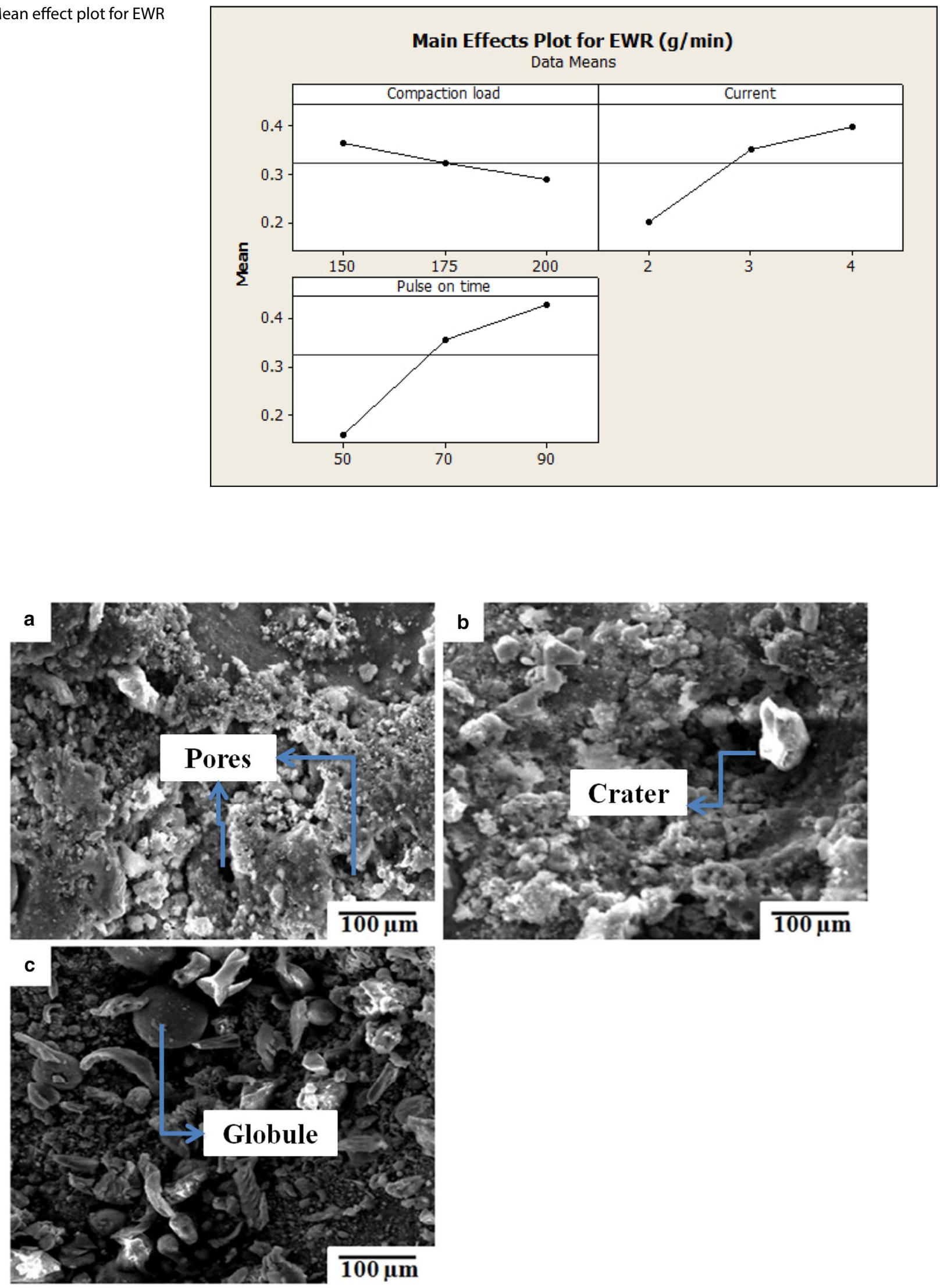

Fig. 7 SEM image of coating deposited a $150 \mathrm{MPa}, 4 \mathrm{~A}$ and $90 \mu \mathrm{s}, \mathbf{b} 175 \mathrm{MPa}, 3 \mathrm{~A}$ and $70 \mu \mathrm{s}$ and c $200 \mathrm{MPa}, 2 \mathrm{~A}$ and $50 \mu \mathrm{s}$ 

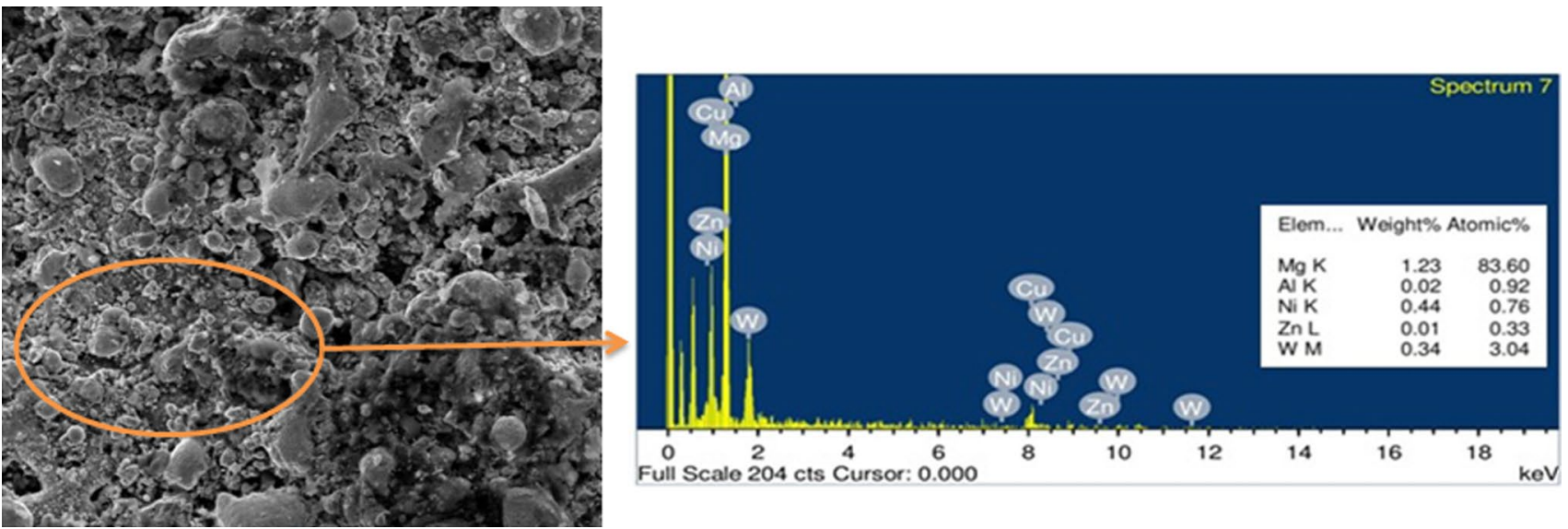

Fig. 8 SEM and EDS plot for WC/Ni composite deposited surface at $150 \mathrm{MPa}, 4 \mathrm{~A}$ and $90 \mu \mathrm{s}$

pulse on time increase, the DR and EWR increase. At high pulse on time, the diameter of the plasma channel is very large, therefore the produced plasma channel crumbles the large amount materials from the electrode and deposited on the surface, which is confirmed by the Elaiyarasan et al. [12]. At low pulse on time, the migration of the electrode material is very low because of low discharge energy, which is not sufficient to melt and vaporize the electrode materials and it was resulted that the small quantity of electrode material transferred on the surface [13]. Hence, DR and EWR decreased. In this condition, uniform deposition was formed with better surface roughness.

\section{Micro hardness}

Micro hardness $(\mathrm{MH})$ is the important characteristic of the deposited surface, which is carried out on the deposited surface using Vicker hardness tester. Three values were taken in the each samples and average was consider as the micro hardness values. The maximum hardness value was achieved at surface deposited with low compaction load, high current and pulse on time. Figure 9 shows the microstructure of the deposited surface with micro hardness values, which was taken in the different region. The average micro hardness value of the deposited surface was $772 \mathrm{HV}$. As said above, at low compaction the micro hardness value is high because of the bulk and lump deposition. Hence, while hardness tests, the hard deposited materials resists the indentation. Hence MH is high at low compaction load. Conversely, at high compaction load the $\mathrm{MH}$ value is minimum due its large diameter of the indentation. Therefore the $\mathrm{MH}$ decreases with increase in compaction load.

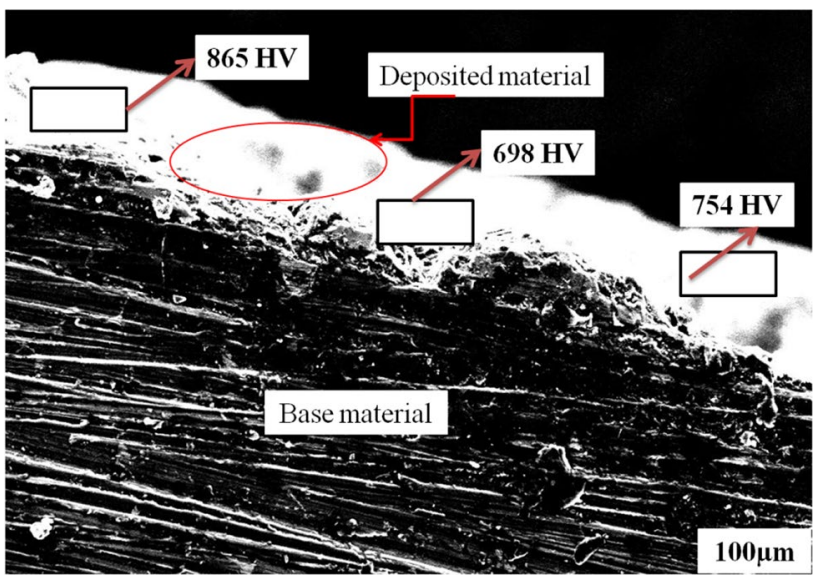

Fig. 9 Microstructure of the deposited surface with micro hardness values

\section{Optimization of parameters on DR and EWR}

In the recent year, various optimization techniques have been introduced in the various manufacturing industries to optimize the machining parameters. But by using some technique, cannot be optimized the parameters with multiple responses in a same time $[14,15]$. However, response surface methodology is very essential tool to optimize the parameters with multi response. The main approach of the optimization is to convert the response into desirability function $\mathrm{d}_{\mathrm{i}}$. The optimized values for each parameters can be determined by the increasing the composite desirability. In this research, the output characteristics are selected to maximize the desirability.

$0<\mathrm{d}_{\mathrm{i}}<1$ 
Fig. 10 Optimization plot for DR and EWR

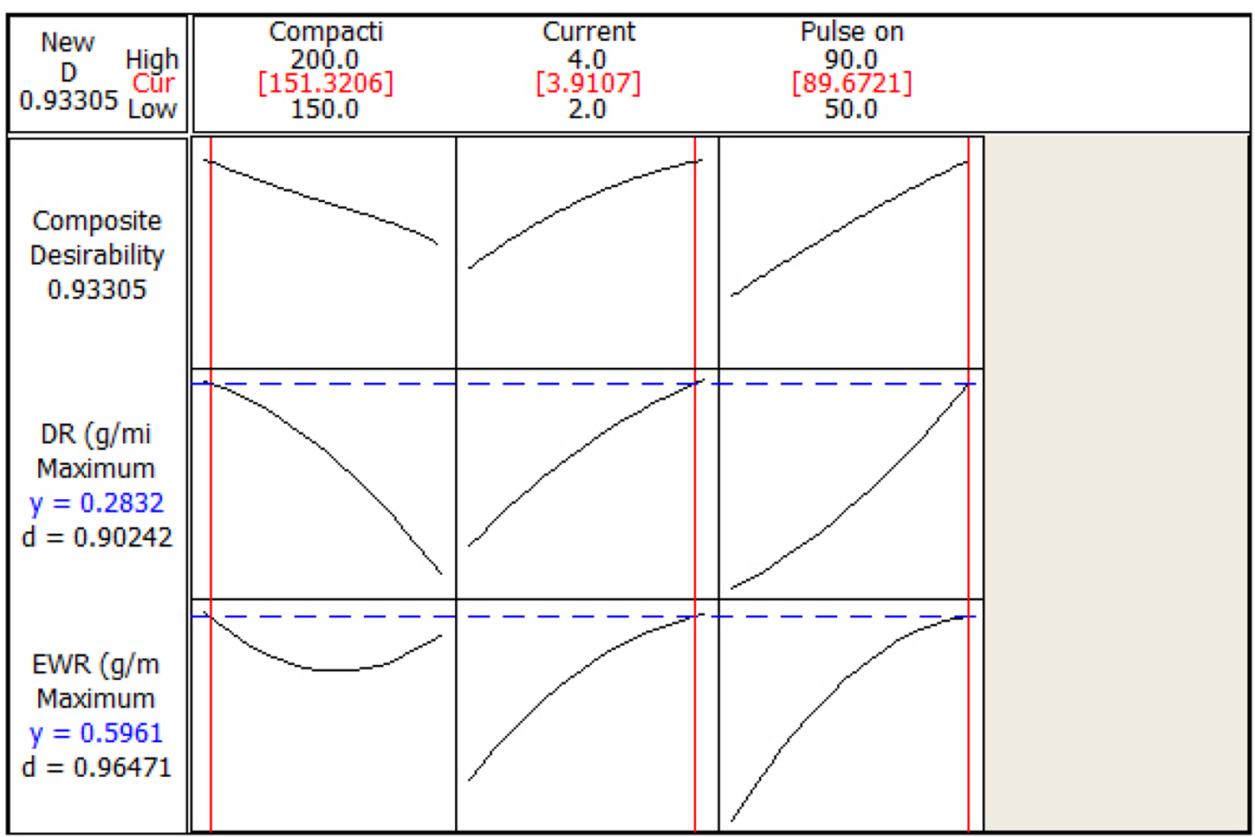

In this investigation, process parameters used in the electrical discharge deposition is optimized. In this research, main aim of the optimization is to maximize the values of DR and EWR. During the optimization, maximum and minimum of experimental values are considered to optimize the parameters and target values also are fixed. The maximum DR of $0.283 \mathrm{~g} / \mathrm{min}$ and EWR of 0.5961 were achieved in the parameter conditions such as compaction load of $151 \mathrm{MPa}$, current of $4 \mathrm{~A}$ and pulse on time of $89 \mu \mathrm{s}$ as shown in Fig. 10. Table 6 shows the validation test results for DR and EWR and desirability for DR and EWR are 0.929 and 0.938 respectively and composite desirability of optimization is 0.933 which is close to 1 . Hence all parameters are within the working limit.

\section{Conclusion}

The present research studied the optimization of process parameters in electrical discharge deposition of ZE41A magnesium alloy using response surface methodology. Different process parameter such as compaction load, current and pulse on time were selected to deposit the electrode materials on the workpiece surface.

DR and EWR increases with increase in current and pulse on time at low compaction load. This is due to the higher spark density which increases the local temperature in the coating zone. Hence large quantity of material dislodged from the electrode and deposited on the workpiece. Conversely, it decreases with increase in compaction load. This may be due to higher bonding strength. When electrode prepare with high compaction load the electrode became fully bonded solid. Even supplied high pulse energy the erosion rate of electrode is less. Thus DR and EWR decreased in high compaction load.

Mathematical models were developed for the EDD characteristics such as deposition rate and EWR to study the effect parameters. In which the compaction load, current and pulse on time are the most significant parameters in this study. The parameters were optimized on DR and EWR using response surface optimizer. The optimized parameters were compaction load of $150 \mathrm{MPa}$, current of $4 \mathrm{~A}$ and pulse on time of $90 \mu \mathrm{s}$.

Table 6 Validation test results for DR and EWR

\begin{tabular}{|c|c|c|c|c|c|c|c|c|c|}
\hline \multirow[t]{2}{*}{ S. no } & \multirow[t]{2}{*}{ Compaction load (MPa) } & \multirow[t]{2}{*}{ Current (Amp) } & \multirow[t]{2}{*}{ Pulse on time $(\mu \mathrm{s})$} & \multicolumn{3}{|c|}{ Deposition rate ( $\mathrm{g} / \mathrm{min})$} & \multicolumn{3}{|c|}{ Electrode wear rate ( $\mathrm{g} / \mathrm{min})$} \\
\hline & & & & Predicted & Actual & \%Error & Predicted & Actual & \%Error \\
\hline 1 & 150 & 4 & 90 & 0.290 & 0.310 & 6.5 & 0.609 & 0.618 & 1.5 \\
\hline
\end{tabular}




\section{Compliance with ethical standards}

Conflict of interest The authors declare that they have no conflict of interest.

\section{References}

1. Prakash C, Singh S, Pruncu Cl, Mishra V, Królczyk G, Pimenov DY, Pramanik A (2019) Surface modification of Ti-6Al-4 V alloy by electrical discharge coating process using partially sintered ti-nb electrode. Materials 12:1006

2. Fotovvati B, Namdari N, Dehghanghadikolaei A (2019) On coating techniques for surface protection: a review. J Manuf Mater Proc 3:28

3. Abu Qudeiri JE, Saleh A, Ziout A, Mourad AHI, Abidi MH, Elkaseer A (2019) Advanced electric discharge machining of stainless steels: assessment of the state of the art, gaps and future prospect. Materials 12:907

4. Elaiyarasan U, Satheeshkumar V, Senthilkumar C (2018) Effect of electrical discharge coating on ZE41A magnesium alloy using sintered WC/Cu composite. J Adv Micro Res 13:381-387

5. Arun I, Yuvaraj C, Selvarani P, Senthilkumaar JS, Thamizhmanii S, Muruganandam P (2019) Synthesis of electrical discharge metal matrix composite coating through compacted semi-sintered electrode and its tribological studies. J Braz Soc Mech Sci Eng 41:213

6. Tyagi R, Pandey K, Mohanty S, Kumar S, Das AK, Mandal A (2019) Optimization of electrical discharge coating deposited of through WS2 and green Cu powder compact mixture electrode. In: Advances in industrial and production engineering: select proceedings of FLAME, $\mathrm{p} 273$

7. Gill AS, Kumar S (2018) Micro-hardness evaluation for surface alloying of $\mathrm{H} 11$ die steel with $\mathrm{Cu}-\mathrm{Cr}-\mathrm{Ni}$ powder metallurgy tool in electrical discharge machining. Proc Inst Mech Eng Part B J Eng Manuf 232:438-450
8. Tijo D, Kumari S, Masanta M (2018) Ceramic-metal composite coating on steel using a powder compact tool electrode by the electro-discharge coating process. Silicon 10:1625-1637

9. Elaiyarasan U, Satheeshkumar V, Senthilkumar C (2018) Experimental analysis of electrical discharge coating characteristics of magnesium alloy using response surface methodology. Mater Res Exp 5:086501

10. Walia AS, Jain V, Srivastava V (2019) Development and performance evaluation of sintered tool tip while EDMing of hardened steel. Mater Res Exp 6:086520

11. Kavimani V, Prakash KS, Thankachan T (2019) Influence of machining parameters on wire electrical discharge machining performance of reduced graphene oxide/magnesium composite and its surface integrity characteristics. Compos Part B Eng 167:621-630

12. Elaiyarasan U, Satheeshkumar V, Senthilkumar C (2019) Microstructure study on electro discharge deposited magnesium alloy with semi sintered and sintered electrode. Mater Res Exp 6:126533

13. Chundru VR, Koona R, Pujari SR (2019) Surface modification of Ti6Al4V alloy using EDMed electrode made with nanoand micron-sized $\mathrm{TiC} / \mathrm{Cu}$ powder particles. Arab J Sci Eng 44:1425-1436

14. Chethan YD, Ravindra HV, Krishnegowda YT (2019) Optimization of machining parameters in turning Nimonic-75 using machine vision and acoustic emission signals by Taguchi technique. Measurement 144:144-154

15. Elaiyarasan U, Satheeshkumar V, Senthilkumar C (2019) Surface modification of ZE41A magnesium alloy using electrical discharge coating with semi sintered electrode. Int J Mach Mach Mater 21:375-389

Publisher's Note Springer Nature remains neutral with regard to jurisdictional claims in published maps and institutional affiliations. 